Euphytica (2006) 151: $79-86$

\title{
Heritabilities and minimum gene number estimates of carrot carotenoids ${ }^{\star}$
}

\author{
Carlos Antonio Fernandes Santos ${ }^{1} \&$ Philipp W. Simon ${ }^{2, *}$ \\ ${ }^{1}$ Embrapa-Semi-Arido, Caixa Postal 23, 56300-970, Petrolina, PE, Brasil; \\ ${ }^{2}$ USDA-ARS Vegetable Crops Research Unit and Department of Horticulture, 1575 Linden Drive, \\ University of Wisconsin, Madison, WI 53706, USA (*author for correspondence: e-mail: psimon@wisc.edu)
}

Received 30 November 2005; accepted 15 February 2006

Key words: carotenes, Daucus carota, HPLC

\section{Summary}

Broad sense heritabilities and gene numbers were estimated for the production of total carotenoids and the major component carotenoids of carrot storage roots: phytoene, $\zeta$-carotene, $\beta$-carotene, $\alpha$-carotene, and lycopene. Two crosses with different backgrounds were evaluated: orange B493 $\times$ white QAL and orange Brasilia $\times$ dark orange HCM. The HCM (high carotene mass selection), Brasilia and B493 parents had both $\alpha$-carotene and $\beta$-carotene, but HCM had proportionally more $\alpha$-carotene. Carotene content in $F_{2}$ populations ranged from $522 \mathrm{ppm}$ to 1714 ppm in Brasilia $\times$ HCM and from 0 to $695 \mathrm{ppm}$ in B493 $\times$ QAL progeny. $F_{2}$ plants segregating for absence of $\alpha$-carotene were identified in B493 $\times$ QAL. Broad-sense heritabilities ranged from $28 \%$ to $48 \%$ for all carotenes except lycopene and phytoene where estimates were 44\% to 89, in the Brasilia $\times$ HCM cross, 4 Ill heritability values exceeded $88 \%$ for the B493 $\times$ QAL cross, except one estimate for lycopene. The estimated number of genes was 4 conditioning $\alpha$-carotene, 2 to 3 each for $\beta$-carotene and total carotenes and one each for $\zeta$-carotene. lycopene and phytoene in the orange $\times$ dark orange cross. In the orange $\times$ white cross, the estimates were 4 genes for $\alpha$-carotene, 1 to 2 each for lycopene and total carotenes and 1 for each of the other carotenes. These results are in general agreement with QTL studies and they provided evidence for continuous inheritance of $\alpha$-carotene, $\beta$-carotene and total carotenoids in the orange $\times$ dark orange cross and discrete inheritance for $\beta$-carotene and total carotenoids in the orange $\times$ white cross.

The biosynthesis of carotenoids is a well established biochemical pathway that has been studied in many plants (Cunningham \& Gantr 1998; Sandmamn 1994), fungi and microorganisms (Sandmann 1994). Vertebrates do not synthesize carotenoids and they ultimately depend on plant carotenoids in their diet for synthesizing their retinoids, such as retinal (the main visual pigment), retinol (vitamin A) and retinoic acid (a substance controlling morphogenesis) (Giuliano et al.,

* Part of thesis "Biometrical studies and quantitative trait loci associated with major products of the carotenoids pathway of carrot (Daucus carota L.)" presented by the iirst author as partial fulfillment of the requirement of the $\mathrm{PhD}$ degree in Plant Breeding and Plant Genetics, UW-Madison, USA, 2001.
2000). Although more than 40 carotenoids have been found to be vitamin A precursors, the main precursor of retinoids is $\beta$-carotene (Simpson 1983).

According to the World Health OrganizationWHO (2001), vitamin deficiency is a public health problem in 118 countries, especially in Africa and South-East Asia, resulting in an estimated 100 to 140 million vitamin A-deficient children, of which 250,000 to 500,000 become blind every year and half of these die within 12 months of losing their sight. Nearly 600,000 women die from childbirth-related causes each year, the vast majority of them attributable to vitamin $\mathrm{A}$ de ficiency. The challenge of this continuing nutritional health problem emphasizes the need to increase and sustain the dietary sources of provitamin A carotenoid
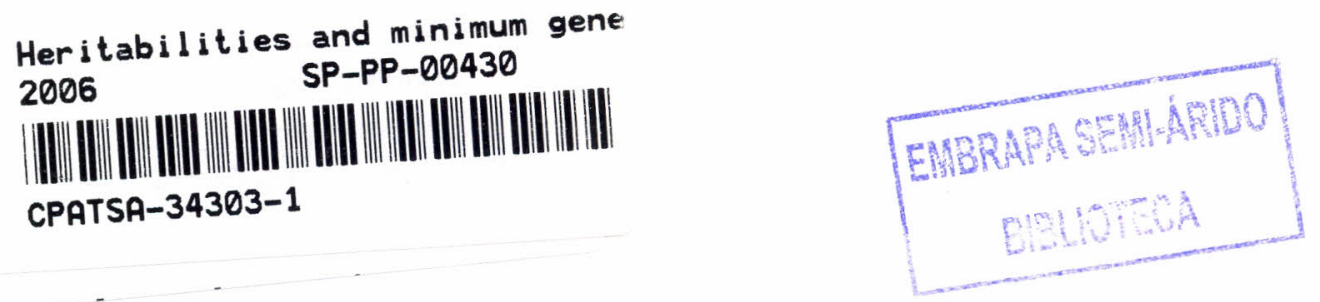
sources. Biotechnological approaches have been employed to achieve this goal (Ye et al., 2000) and numerous horticultural crops are already good sources of provitamin A carotenoids, but outside of heritability estimates for carotenoid content in a very few crops such as chickpea (Abbo et al., 2005) and tomato (SalibaColombani et al., 2001; Stevens, 1986), genetic and environmentai variables affecting carotene content have not been studied in most of these crops (Simon, 1992).

The storage root of modern carrot contains carotenoids that account for their orange, yellow, and red color which varies widely in intensity (Buishand \& Gabelman 1979; Simon et al., 1989, Surles et al., 2004). Total carotenoid content (fresh weight basis) ranges from 64 to up $600 \mu \mathrm{g} / \mathrm{g}$ in orange carrot, 15 to $71 \mu \mathrm{g} / \mathrm{g}$ in yellow carrot, 0 to $1.5 \mu \mathrm{g} / \mathrm{g}$ in white carrot and around $100 \mu \mathrm{g} / \mathrm{g}$ in red carrot (Buishand \& Gabelman 1979; Laferriere \& Gabelman, 1968; Surles et al., 2004).

Since the original observations of carrot storage root color variation in progeny of white-rooted wild carrot by Vilmorin in 1859 , the inheritance of this trait has been the subject of several studies. Laferriere and Gabelman (1968) inferred a complex pattern of inheritance and Buishand and Gabelman (1979) investigated carrot color inneritance by crossing uniformly colored roots to various roots for which the xylem differs in color from the phloem. They concluded that 1) a single major gene $(Y)$ was responsible for the differences in progenies of orange $x$ orange (phloem)-white (xylem) color and 2) another major gene was responsible for the difference between yellow $x$ orange or between orange (phloem)-yellow (xylem) $\times$ orange crosses $\left(Y_{2}\right)$. Simon (1996) and Bradeen and Simon (1998) studied the inherirance of $Y_{2}$ in diverse generic backgrounds and concluded it was the single major locus accounting for the color differences described by Buishand and Gabelman. While Buishand and Gabelman (1979) attempted to categorize root color into discrete intensity classes, continuous variation was observed. More recently we have identified QTL for the major component carotenoids in carrot storage roots (Santos \& Simon 2002), but their heritabilities have not been reported.

In this study we urilized rwo crosses of carrot with very different backgrounds to estimate the broad-sense heritabilities and number of genes involved in the production of phytoene, lycopene, $\zeta$-carotene, $\beta$-carotene, $\alpha$-carotene and total carotenoids. These are important estimations to help carrot breeding programs, to understand the evolution of this pathway and to provide a basis for comparison with quantitative trait loci studies.

\section{Material and methods}

\section{Plant material}

The experimental populations were developed from two unrelated crosses, B493 × Queen Anne's Lace $(\mathrm{QAL})$ and Brasilia $\times$ High Mass Carotene (HCM). Individual piants from each parental line or population were intercrossed and single $F_{1}$ plants were selfpollinated to generate the $F_{2}$ populations evaluated for both crosses.

$B 493 \times Q A L$

This population was included to study the factors that condition the accumulation of carotenoids (orange parent) in the presence of factors that result in no carotenoid production (white parent). B493 is an inbred dark orange carrot developed with carotene content ranging from 180 to 210 ppm fresh weight basis (Simon et al., 1990). QAL is a white (no carotenoids accumulated) wild carrot (D. carota var. carota) well distributed in temperate regions of North and South America, and from the Atlantic coast of Eastem Europe to western China (Rubatzky et al., 1999). The population evaluated was derived from a single $F_{1}$ plant from a cross between B493 and QAL from Madison, WI, USA, in 1989.

\section{Brasilia $\times H C M$}

This population was included to study the effects of loci contributing to carotenoid accumulation when both parents accumulate carotenoids but in significantly different quantities. HCM is a population with an average carotene content ranging from 460 to 499 ppm that was developed from a cross berween European and Asian carrot germplasm (Simon et al., 1989). Brasilia is a typical orange population adapted to warner Brazilian production areas (Vieira et al., 1983; Hamerschmidt, 1993) with a carotene content ranging from 35 to 85 ppm (P.W. Simon, personal communication).

Parental lines B493, QAL, Brasília and HCM, and the $F_{1}$ and $F_{2}$ progeny of B493 $\times$ QAL and Brasilia $\times$ HCM were grown at Palmyra, Wisconsin, USA. From 12 to 48 parental piants, 3 to $10 F_{1}$ piants and 157 to $178 F_{2}$ plants were harvested and stored at $2 \mathrm{C}$ until sampling for carotenoid type and anount (Table 1). Roots were vernalized and seed produced to advance to next generation. Slices for carotenoid quantification around $2 \mathrm{~g}$ were sampled from the middle portion of freshly washed root, weighed, wrapped in cheesecloth and frozen for at least $48 \mathrm{hrs}$ at $-80^{\circ} \mathrm{C}$. Frozen-slices 
Table 1. Means, standard etroc of means, maximum and minimum values, in ppon or $\mu \mathrm{g} / \mathrm{g}$ (dry weight), for $\zeta$-carotene, $\alpha$-carotene, $\beta$-carotene, phytoene, lycopene and total carotenoids of the parents, $F_{1}$ and $F_{2}$ plants of crosses B493 $\times$ QAL and Brasilia $\times$ HCM.

\begin{tabular}{|c|c|c|c|c|c|}
\hline \multirow[b]{2}{*}{ Character/Population } & \multirow[b]{2}{*}{ Mean } & \multirow[b]{2}{*}{$\mathrm{n}$} & \multirow[b]{2}{*}{ Means standard eñor } & \multicolumn{2}{|c|}{ Range } \\
\hline & & & & Low & High \\
\hline \multicolumn{6}{|l|}{$\zeta$-carotene } \\
\hline Brasília & 64.6 & 19 & 7.21 & 29.0 & 123.7 \\
\hline $\mathrm{HCM}$ & 117.3 & 12 & 18.3 & 41.1 & 233.6 \\
\hline Brasília $\times \mathrm{HCM}-F_{1}$ & 88.0 & 10 & 20.0 & 25.5 & 233.7 \\
\hline Brasília $\times \mathrm{HCM}-F_{2}$ & 125.0 & 157 & 6.7 & 4.4 & 417.1 \\
\hline B493 & 187.6 & 48 & 12.1 & 27.6 & 370.3 \\
\hline QAL & 0.0 & 34 & 0.0 & 0.0 & 0.0 \\
\hline $\mathrm{B} 493 \times \mathrm{QAL}-F_{1}$ & 0.0 & 3 & 0.0 & 0.0 & 0.0 \\
\hline $\mathrm{B} 493 \times \mathrm{QAL}-F_{2}$ & 8.0 & 178 & 2.5 & 0.0 & 271.1 \\
\hline \multicolumn{6}{|l|}{ ú-carotene } \\
\hline Brasilia & 133.2 & 19 & 17.1 & 19.1 & 320.1 \\
\hline $\mathrm{HCM}$ & 697.7 & 12 & 95.6 & 255.9 & 1224.4 \\
\hline Brasília $\times \mathrm{HCM}-F_{1}$ & 318.5 & 10 & 55.5 & 113.5 & 561.3 \\
\hline Brasilia $\times \mathrm{HCM}-F_{2}$ & 452.8 & 157 & 16.6 & 10.5 & 1100.4 \\
\hline B493 & 266.4 & 48 & 11.2 & 31.0 & 390.8 \\
\hline QAL & 0.0 & 34 & 0.0 & 0.0 & 0.0 \\
\hline $\mathrm{B} 493 \times \mathrm{QAL}-F_{1}$ & 0.0 & 3 & 0.0 & 0.0 & 0.0 \\
\hline $\mathrm{B} 493 \times \mathrm{QAL}-F_{2}$ & 4.7 & 178 & 2.3 & 0.0 & 285.5 \\
\hline \multicolumn{6}{|l|}{$\beta$-carotene } \\
\hline Brasilia & 232.1 & 19 & 27.6 & 83.4 & 552.0 \\
\hline HCM & 584.5 & 12 & 74.9 & 211.2 & 999.4 \\
\hline Brasília $\times \mathrm{HCM}-F_{1}$ & 278.2 & 10 & 41.9 & 109.2 & 500.0 \\
\hline Brasília $\times \mathrm{HCM}-F_{2}$ & 366.3 & 157 & 16.2 & 4.4 & 911.6 \\
\hline B493 & 460.9 & 48 & 19.6 & 147.7 & 704.8 \\
\hline QAL & 0.0 & 34 & 0.0 & 0.0 & 0.0 \\
\hline $\mathrm{B} 493 \times \mathrm{QAL}-F_{\mathrm{L}}$ & 0.0 & 3 & 0.0 & 0.0 & 0.0 \\
\hline $\mathrm{B} 493 \times \mathrm{QAL}-F_{2}$ & 13.8 & 178 & 3.6 & 0.0 & 299.0 \\
\hline \multicolumn{6}{|l|}{ Phytoene } \\
\hline Brasília & 157.3 & 19 & 26.0 & 62.3 & 438.9 \\
\hline HCM & 412.4 & 12 & 56.0 & 147.2 & 788.4 \\
\hline Brasília $\times \mathrm{HCM}-F_{1}$ & 172.0 & 10 & 14.0 & 114.8 & 256.5 \\
\hline Brasília $\times \mathrm{HCM}-F_{2}$ & 303.1 & 157 & 17.5 & 7.3 & 1049.5 \\
\hline B493 & 500.4 & 48 & 24.3 & 246.1 & 796.1 \\
\hline QAL & 0.0 & 34 & 0.0 & 0.0 & 0.0 \\
\hline $\mathrm{B} 493 \times \mathrm{QAL}-F_{1}$ & 0.0 & 3 & 0.0 & 0.0 & 0.0 \\
\hline $\mathrm{B} 493 \times \mathrm{QAL}-F_{2}$ & 16.1 & 178 & 4.4 & 0.0 & 406.9 \\
\hline \multicolumn{6}{|l|}{ Lycopene } \\
\hline Brasilia & 8.9 & 19 & 1.6 & 2.5 & 29.5 \\
\hline HCM & 31.9 & 12 & 6.7 & 7.2 & 77.1 \\
\hline Brasília $\times \mathrm{HCM}-F_{1}$ & 19.5 & 10 & 4.3 & 48.1 & 3.7 \\
\hline Brasília $\times \mathrm{HCM}-F_{2}$ & 35.2 & 157 & 1.5 & 0.0 & 130.4 \\
\hline B493 & 18.1 & 48 & 2.0 & 2.4 & 66.2 \\
\hline QAL & 0.0 & 34 & 0.0 & 0.0 & 0.0 \\
\hline $\mathrm{B} 493 \times \mathrm{QAL}-F_{1}$ & 0.0 & 3 & 0.0 & 0.0 & 0.0 \\
\hline $\mathrm{B} 493 \times \mathrm{QAL}-F_{2}$ & 1.8 & 178 & 0.8 & 0.0 & 103.5 \\
\hline \multicolumn{6}{|l|}{ Total carotenoids } \\
\hline Brasília & 454.5 & 19 & 37.1 & 194.6 & 882.0 \\
\hline HCM & 1619.5 & 12 & 139.5 & 955.0 & 2346.4 \\
\hline Brasilia $\times \mathrm{HCM}-F_{1}$ & 781.2 & 9 & 87.8 & 1163.1 & 450.3 \\
\hline Brasília $\times \mathrm{HCM}-F_{2}$ & 942.7 & 160 & 27.1 & 98.0 & 1714.1 \\
\hline $\mathrm{B} 493$ & 946.5 & 48 & 33.9 & 414.0 & 1490.1 \\
\hline QAL & 12.9 & 34 & 4.0 & 0.0 & 129.5 \\
\hline $\mathrm{B} 493 \times \mathrm{QAL}-F_{1}$ & 2.9 & 3 & 0.8 & 1.3 & 3.8 \\
\hline $\mathrm{B} 493 \times \mathrm{QAL}-F_{2}$ & 64.2 & 182 & 8.6 & 0.0 & 695.5 \\
\hline
\end{tabular}


were placed into a Virtis Lyophilizer (Model No. $10-$ 146MR-BA) and freeze-dried for 72 hrs.

\section{Quantification of total carotene}

The dry weight of lyophilized carrot slices was recorded and samples were processed as described by Simon and Wolff (1987). Briefly, individual samples were chopped with a razor blade, suspended in pure and water free hexane, and ground with Virtis blender at 65,000 rpm for three minutes while chilled in ice to minimize isomerization. The solution was filtered twice and any trace of water was removed through an additional filter with sodium sulfate. The purified solution was then brought to volume of a $100 \mathrm{ml}$ and quantified at the $450 \mathrm{~nm}$ wavelength in a Gilford Spectophotometer. An estimate of "total carotenoid" concentration was obtained by comparing mean sample absorbance at $450 \mathrm{~mm}$ of each individual sample to a standard curve of $\beta$-carotene.

\section{Quantification of major carotenoids by}

high-performance liquid chromatography

To prepare the samples for high-performance liquid chromatography (HPLC) analysis, $4.0 \mathrm{ml}$ of each hexane-carotenoid solution was transferred to a $5.0 \mathrm{ml}$ brown glass vial and stored in the refrigerator at $4{ }^{\circ} \mathrm{C}$.

The HPLC equipment used consisted of a Waters $6000 \mathrm{~A}$ pump, a Waters WISP 710B autosampler, and a Waters 996 Photodiode Array Detector (Waters Associates, Milford, MA). Separations were performed with the system of Khachick et al. (1992), using a Rainin Microsorb-MV $5 \mu \mathrm{m} \mathrm{C18} 25 \mathrm{~cm} \times 4.6 \mathrm{~mm} 100 \mathrm{~A}$ column, a $2.5 \mathrm{~cm} \times 4.6 \mathrm{~mm}$ Bondapak C18/Corasil guard column, and a mobile phase of acetonitrile: methylene chloride: methanol, $55: 23: 22$ at a flow rate of $1 \mathrm{ml} / \mathrm{min}$. Data were collected from 192 to $600 \mathrm{~mm}$ (1.2 $\mathrm{nm}$ resolution), at $0.5 \mathrm{~s}$ intervals, and peaks were quantified using Millemium version 2.1 software (Waters Corporation, 1994). Resulting data were used to estimate phytoene, lycopene, $\zeta$-carotene, $\beta$-carotene and $\alpha$-carotene contents. Synthetic $\beta$-carotene (Sigma C9750) was used as a reference standard in separate sampling and the identity of individual compounds was confirmed by an evaluation of the absorption spectra. Lycopene, $\zeta$-carotene, $\beta$-carotene and $\alpha$-carotene were quantified at wavelength of $404 \mathrm{~nm}$ absorbance with retention times of around 12,14, 16 and $17 \mathrm{~min}$, respec- tively (Figure 1A, 1B and 1C). Phytoene was quantified. at $287 \mathrm{~nm}$ with a peak around $20 \mathrm{~min}$ (Figure 1D) as reported by Simon and Wolff (1987) and Khachik et al. (1989).

\section{Statistical analysis}

Means, variances, standard error of means and minimum and maximum values for parental lines, $F_{4}$ and $F_{2}$ populations for total carotenoid, phytoene, $\zeta$ carotene, $\beta$-carotene, lycopene and $\alpha$-carotene were estimated using the Univariate procedure (SAS 1989). All carotenoid concentrations are given on a dry weight basis in this study. Tests for normality of all traits in the $F_{2}$ populations were obtained with kurtosis and the Wilk-Shapiro test in the Univariate procedure.

Estimates of the minimum number of genes influencing total carotenoid, phytoene, $\zeta$-carotene, $\beta$ carotene, lycopene and $\alpha$-carotene were determined by the methods of first moments, also called Sewall Wright's estimator, and applying the generalization presented by Lande (1981). Two estimates were obtained from the available data with the equations presented by Lande (1981): Effective number of factors $\left(n_{E}\right)=\left(\mu_{P_{2}}-\mu_{P_{1}}\right)^{2} /\left(8 \sigma_{S}^{2}\right) \leq$ the actual number of factor $(n)$. The two estimates for $\sigma_{S}^{2}$ were obtained with $\sigma_{S}^{2}=\sigma_{F_{2}}^{2}-\sigma_{F_{1}}^{2}$ (estimate 1) and $\sigma_{S}^{2}=$ $\sigma_{F_{2}}^{2}-\left[\frac{1}{2} \sigma_{F_{1}}^{2}+\frac{1}{4} \sigma_{P_{1}}^{2}+\frac{1}{4} \sigma_{P_{2}}^{2}\right]$ (estimate 2), where $\sigma_{S}^{2}$ is the gerietic varianice segregating in the $F_{2}$ populationi, $\sigma_{F_{2}}^{2}$ is the total variance of $F_{2}$ due to the genetic and the enviromment variances, $\sigma_{F}^{2}$ is the enviroumental variance of $F_{1}$ and $\sigma_{P_{1}}^{2}$ and $\sigma_{P_{2}}^{2}$ are environmental variances of both parent lines. To estimate the minimum numbers of loci or factors, both datasets were transformed to the logarithmic scale plus one in order to make the genetic variance additive, as recommended by Lande (1981). Standard errors of minimum number of factors estimates were performed as described by Lande (1981).

An estimate of heritability for total carotenoid. phytoene, $\zeta$-carotene, $\beta$-carotene, lycopene and $\alpha$ carotene was calculated with $h^{2}=\left(\sigma_{R_{2}}^{2}-\sigma_{F_{1}}^{2}\right) / \sigma_{F_{2}}^{2}$ formula. According to Burton (1951) this formula gives upward bias and the estimates so obtained should be considered as the maximum heritability since the genetic variance in $F_{2}-F_{1}$ will include total genetic variance (due ro additive effects, dominance deviations and the interaction of nonallelic genes) and variance due to interaction of genotypes and the environment. 

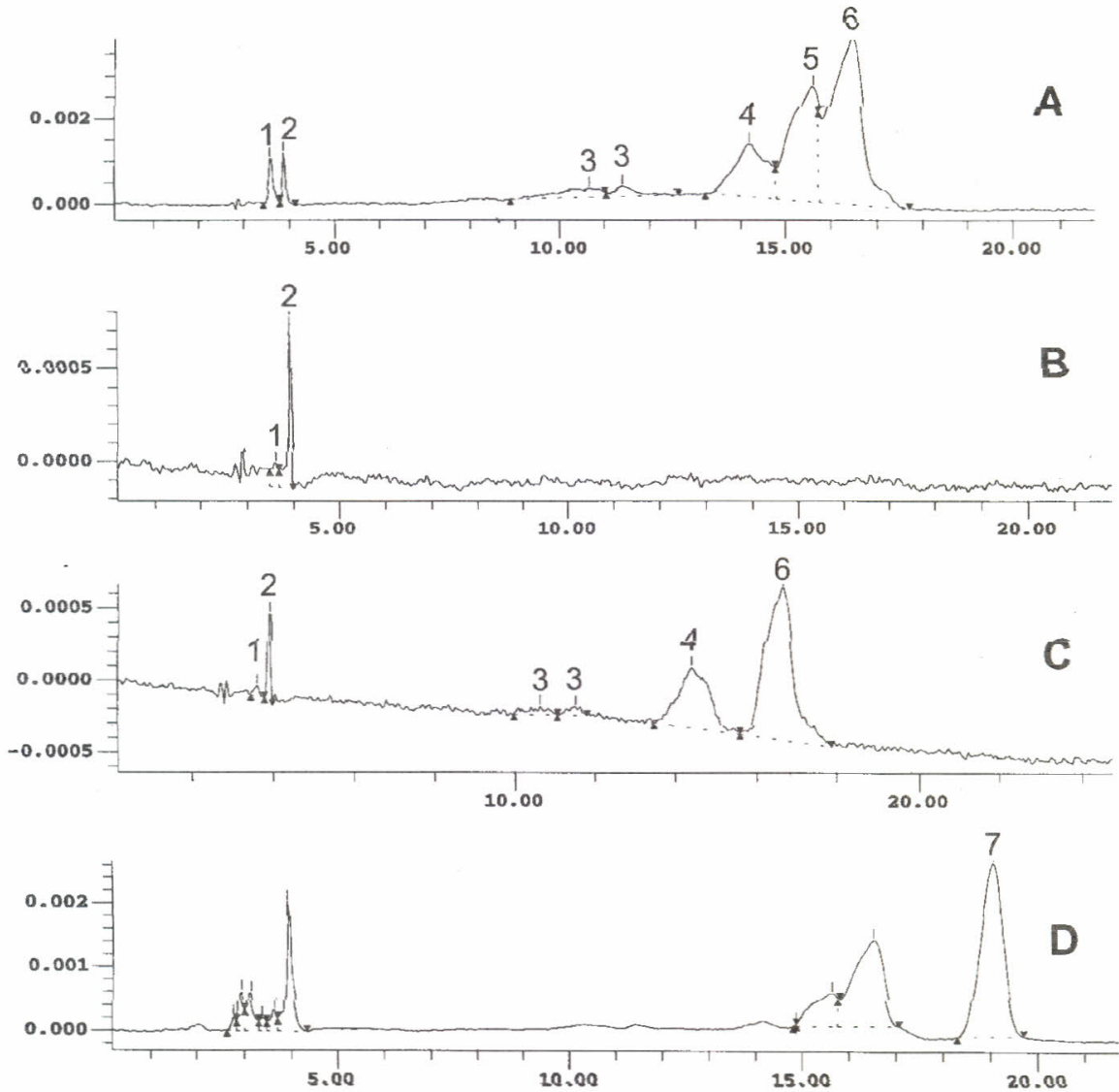

Figure 1. Representative HPLC chromatograms at $404 \mathrm{~nm}$ absorbance from roots of carrots: A) a typical sample of 'Brasília'; B) a white sample of $Q A L ; C$; a $F$ plan segregating for absence of a-carotene in the cross B493 $\times$ ' QAL; and D) a representative IML $C$ chromatogram at $287 \mathrm{~nm}$ absorbance from a sample of 'Brasília'. Peaks correspond to (1) lutein or zeaxanthin, (2) hexane noise, (3), lycopene, (4) $\zeta$-carotene, (5) $\alpha$-carotene, (6) $\beta$-carotene and (7) phytoene.

\section{Results and discussion}

\section{Identification of major carotenoid products by HPLC chromatograms}

All major carotenes were present in the parental lines B493, Brasilia and HCM, and absent in QAL, as expected (Figure 1). Chromatograms revealed a higher relative content of $\alpha$-carotene, compared to $\beta$-carotene, in the HCM line, suggesting that much of the total carotene increase realized in selection of HCM resulted in an increase in $\alpha$-carorene. Early selection on HCM population had presented $\beta$-carotene and $\alpha$-carotene accounting for $50 \%$ and $40 \%$ of total carotenes, respectively (Simon \& Wolf, 1987).
$F_{2}$ plants segregating for absence of $\alpha$-carotene peak were observed in the cross B493 $\times$ QAL $F_{2}$ (Figure 1). In the case of $\alpha$-carotene, with one $\hat{\beta}$ and one $\varepsilon$ ring, two different enzymes, lycopene $\beta$ cyclase and lycopene $\varepsilon-c y c l a s e$, are involved (Sandmann 1994). Whether the route to $\alpha$-carotene is only via $\varepsilon$ ring first or can also proceed via , $B$ ring first has not been determined (Cumningham \& Gantt, 1998). Our data support the hypothesis that $\alpha$-carotene is produced after the synthesis of $\beta$-carotene in carrot. Lines free of $\alpha$-carotene are being developed not only for genetics studies, but also to improve the provitamin A content, since, according Sharman (1983) and van der Berg et al. (2000), $\alpha$-carotene has less provitamin A activity than $\beta$-carotene. 
Table 2. Estimation of broad sense heritability and minimum number of genes or factors, with standard ercors of estimates, controlling the inheritance of $\zeta$-carotene, $\alpha$-carotene, $\beta$-carotene, phytoene, lycopene and total carotenoids ("total caro") in two $F_{2}$ populations of carrot.

\begin{tabular}{|c|c|c|c|c|c|c|c|c|}
\hline \multirow[b]{3}{*}{ Character } & \multicolumn{4}{|c|}{ Brasilia $\times \mathrm{HCM}$} & \multicolumn{4}{|c|}{$\mathrm{B} 493 \times \mathrm{QAL}$} \\
\hline & \multicolumn{2}{|c|}{ Heritability } & \multicolumn{2}{|c|}{ Number of factors and standard error } & \multicolumn{2}{|c|}{ Heritability } & \multicolumn{2}{|c|}{ Number of factors and standard error } \\
\hline & $1^{1}$ & $2^{2}$ & $1^{1}$ & $2^{2}$ & $1^{1}$ & $2^{2}$ & $1^{1}$ & $2^{2}$ \\
\hline$\zeta$-carotene & 0.46 & 0.48 & $0.17 \pm 0.1$ & $0.18 \pm 0.1$ & 0.92 & 0.98 & $1.13 \pm 0.2$ & $1.05 \pm 0.2$ \\
\hline$\alpha$-carotene & 0.32 & 0.36 & $4.00 \pm 3.2$ & $3.50 \pm 3.0$ & 0.83 & 0.95 & $3.93 \pm 0.8$ & $3.47 \pm 0.7$ \\
\hline$\beta$-carotene & 0.28 & 0.42 & $1.67 \pm 1.3$ & $2.52 \pm 2.3$ & 0.97 & 0.99 & $1.12 \pm 0.2$ & $1.10 \pm 0.2$ \\
\hline Phytoene & 0.53 & 0.89 & $0.22 \pm 0.2$ & $0.60 \pm 0.4$ & 0.97 & 0.99 & $1.12 \pm 0.2$ & $1.10 \pm 0.2$ \\
\hline Lycopene & 0.44 & 0.66 & $0.36 \pm 0.2$ & $0.53 \pm 0.4$ & 0.51 & 0.88 & $1.83 \pm 0.4$ & $1.27 \pm 0.3$ \\
\hline Total caro & 0.38 & 0.45 & $2.92 \pm 2.0$ & $3.45 \pm 2.4$ & 0.98 & 0.89 & $1.68 \pm 0.3$ & $0.90 \pm 0.2$ \\
\hline
\end{tabular}

Based on ${ }^{1 /} \sigma_{S}^{2}=\sigma_{F_{2}}^{2}-\sigma_{F_{!}}^{2}$ and ${ }^{2 /} \sigma_{S}^{2}=\sigma_{F_{2}}^{2}-\left[\frac{1}{2} \sigma_{F_{!}}^{2}+\frac{1}{4} \sigma_{P_{!}}^{2}+\frac{1}{4} \sigma_{P_{2}}^{2}\right]$.

Quantificatiope ard descriptive statistics of total carotenoids and major carotenes

Parental lines of each cross presented large differences among them for all carotenoids products analyzed (Table 1). Significant differences among parental limes is a requirement for the accurate estimation of the number of genes involved in the control of characters, as it is for mapping and quantitative traits loci (QTL) studies. Carotene concentrations observed in the parental lines in this study were comparable to those reported in previous studies.

Brasilia $\times \mathrm{HCM} F_{2}$ plants with values higher than the higher value parent were observed in characters $\zeta$-carotene, phytoene and lycopene, and plants segregating with less carotene than the lower parent value were observed in all characters. Transgressive segregation was not observed in the B493 $\times$ QAL cross, except for lycopene, indicating that selection in the carotenoid pathway is a long-term selection process, with several genes interacting to increase the content of each carotenoid. These basic descriptive statistics are very important to estimate the broad sense heritability and the number of loci involved in the inheritance of the carotenoid enzyme pathway and this study is the first to report comprehensive estimates of them.

Since the storage roots of most plants contained no carotenoiu's in the $\mathrm{B} 493 \times \mathrm{QAL} F_{2}$ population, all characters deviated strongly from the normal distribution, with $p$-values less than 0.0001 and kurtosis values greater than 12 . In the Brasilia $\times \mathrm{HCM} F_{2}$ population, the normal distribution fit very well for $\alpha$-carotene and total carotenoids, with moderate fit for $\beta$-carotene. Non-significant Wilk-Shapiro test and kurtosis values around zero suggests the normal distribution probabil- ity of the dataset (SAS 1589). Lycoperte, phytoene and $\zeta$-carotene, in the Brasilia $\times$ HCM cross had kurtosis values less than 3.5 and Shapiro-Wilk tests with $p$ values less than 0.0001 , indicating departure from the normal distribution.

Broad-sense heritability and minimum number of genes involved in the inheritance of major carotenoids in carrot

Heritability values ranged from $28 \%$ to $48 \%$ for $\alpha$ carotene, $\zeta$-carotene, $\beta$-carotene and total carotenoids, from $44 \%$ to $66 \%$ for lycopene, and from $53 \%$ to $89 \%$ for phytoene in the cross Brasilia $\times$ HCM (Table 2). The heritability values were higher for all characters in the cross B493 $\times$ QAL and exceeded $90 \%$ for most estimates. Since we found almost no products of the carotenoid pathway accumulated in the orange $x$ white cross, as also reported early by Laferriere and Gabelman (1968), it is likely that the small number of $F_{1}$ plants evaluated did not bias the estimates of heritabilities and minimum number of genes. To date there are very few reports on heritabilities in carrot and none with carotenoid pathway products so comparisons to other studies are not possible. The broad sense heritabilities estimated here should be considered as the maximum values, regardless of how many plants were evaluated.

The estimated number of factors was 4 for $\alpha$ carotene, 2 to 3 each for $\beta$-carotene and total carotenes and one each for $\zeta$-carotene, lycopene and phytoene in the Brasilia $\times$ HCM cross, whereas only 1 or 2 genes condition all characters except for $\alpha$-carotene where 3 or 4 genes are estimated in the B493 $\times$ QAL cross (Table 2). The two methods used to estimate minimum 
numbers of genes provided similar values for all traits in both populations. No standard errors of minimum number of factors (Table 2) exceeded the estimated minimum number of factors and these two diverse populations gave quite similar estimates, so it is valid to infer that these numbers are accurate. The standard error estimates were similar to the minimum number of factors in the Brasilia $\times$ HCM cross. The higher estimate for genes conditioning $\alpha$-carotene in the B493 $x$ QAL cross may be expected as we observed a single gene controlling its presence among orange-rooted segregants in this cross. Our estimates are similar to those by Laferriere and Gabelman (1968) who reported that at least three major genes separate orange storage root color from white.

Considering total carotenoid as an indirect measure of color, the present study suggests two major loci as the minimum number that are separating orange from white carrot in this study. Based on the estimation from $\zeta$-carotene, phytoene and lycopene accumulation, it is hypothesized that the primary difference between white and orange carrots results from an enzymatic change blocking carotenoid accumulation early in the pathway.

This study presents evidence that $\beta$-carotene and $\alpha$-carotene quantity, the two major products of the carotenoid pathway in carrot, varied in a continuous pattern fitting a normal distribution among progeny of a cross between orange $x$ dark orange carrots, while discrete segregation with significant difference from a normal distribution was observed in a cross of orange $x$ white carrots. A larger number of genes was estimated in orange $x$ dark orange than in orange $x$ white cross, reinforcing this hypothesis of continuous and discrete inheritance of final produsts of the carotenoid pathway in carrot. Wild white-rooted carrots have been used as an important source of genetic variation for reproductive and disease resistance traits by carrot breeders, and further screening of wild carrot germplasm indicates it to be a source for more traits of interest (Simon, 2000). These results of this study indicate that retrieval of orange-rooted progeny in crosses with wild whiterooted carrots can be achieved with relative ease.

\section{Acknowledgments}

This research was supported by Initiative for Future Agriculture and Food Systems Grant no. 2000-4258 from the USDA Cooperative State Research, Education, and Extension Service and by the California Fresh Carrot Advisory Board.

\section{References}

Abbo, S., C. Molina, R. Jungmann, M.A. Grusak, Z. Berkovitch, R. Reifen, G. Kahl, P. Winter \& R. Reifen, 2005. Qtl governing carotenoid concentration and weight In seeds of chickpea (Cicer arietinum L.). Theor. Appl. Genet. 111: 185-195.

Bradeen, J.M. \& P.W. Simon, 1998. Conversion of an AFLP fiagment linked to the carrot $\mathrm{Y}_{2}$ locus to a simple, codominant, PCR-based marker form. Theor: Appl. Gemet. 97: 960 90 ?

Buishand, J.G. \& W.H. Gabelman, 1979. Investigations of color and carotenoid content in phloem and xylem of carrot roots (Daucus carota L.). Euphytica 28: 611-632.

Buton, G.W., 1951. Quantitative inheritance in pearl millet ( $P$ ennisetum glausumi). Agson. I. 43: 409-417.

Cunningham, F.X. \& E. Gantt, 1998. Genes and enzymes of carotenoid biosynthesis in plants. Ann. Rev. Plant Physio. Plant Molec. Biol. 49: 557-583.

Giuliano, G., R. Aquilani \& S. Dharmapuri, 2000. Metabolic engineering of plant carotenoids. Trends Plant Sci. 5: $406-$ 409 .

Hamerschmidt, I., 1993. Produção de hortaliças e assistência técnica no Brasil. Hortic. Bras. 11: 156-157.

Khachik, F., G.R. Beecher, M.B. Goli \& W. Lusby, 1994. Separation and quantification of carotenoids in foods. Methods Enzymol. 213: $347-359$

Laferriere, L. \& W.H. Gabelman, 1968. Inheritance of color, total carotenoids, alpha-carotene, and beta-carotene in carrots, Daucus carota L. Proc. Am. Soc. Hortic. Sci. 93: 408-411.

Lande, R., 1981. The minimum number of genes contributing to quantitative variation hetween and within ponulations. Genetics 99: $541-553$.

Lincoln, R.E. \& J.W. Porter, 1950. Inheritance of beta-carotene in tomatoes. Genetics 35: 200-2'1'

Rubatzky, V.E., C.F. Quiros \& P.W. Simon, 1999. Carrots and Related Vegetable Umbelliferae. CABI Publishing, Wallingford.

Saliba-Colombani, V., M. Causse, D. Langlois, J. Philouze \& M. Buret, 2001. Genetic analysis of organoleptic quality in fresh maket tonato. 1. Mapping QTL for physical and chemical traits. Theor. Appl. Genet. 102: 259-272.

Sandmann, G., 1994. Carotenoid biosynthesis in microorganisms and prants. Eur. J. Biochem. 223: T-24.

Santos, C.A. \& P.W. Simon, 2002. QTL analyses reveal clustered loci for accumulation of major provitamin $A$ carotenes and lycopene in carrot roots. Molec. Genet. Genomics 268: $122-$ 129.

SAS, 1989. SAS/STAT USE's Guide, Version f, Fouth Edition, Volume 2. SAS Institute Inc., Cary.

Sharman, I.M., 1983. Symposium on 'vitamin $A$ in nutrition and disease'. Proc. Nutr. Soc. 42: 1-17.

Simon, P.W. Genetic Improvement of Vegetable Carotene Content, 1992. In: D.D. Bills \& S. Kung (eds), Biotechnology and nutrition, pp. 291-300. Butterworth-Heinemann, Boston.

Simon, P.W., 1996. Inheritance and expression of purple and yellow storage root color in carror. J. Thered 87: 63 -60.

Simon, P.W., 2000. Domestication, historical development, and modern breeding of carrot. Plant Breed. Rev. 19: 157-190.

Simon, P.W. \& X.Y. Wolft, 1987. Carotenes in typical and dark orange carrots. J. Agric. Food Chem. 35: 1017-1022

Simon, P.W., X.Y. Wolti, C.E. Peterson, D.S. Kammerlohr, V.E. Rubatzky, J.O. Strandberg, M.J. Bassett \& J.M. White, 1989. High Carotene Mass carrot population. HortScience 24: 174. 
Simon, P.W., C.E. Peterson \& W.H. Gabelman, 1990. B493 and B9304, carrot inbreds for use in breeding, genetics, and tissue culture. HortScience 25: 815 .

Simpson, K.L., 1983. Relative value of carotenoids as precursors of vitamin A. Proc. Nutr. Soc. 42: 7-17.

Stevens, M.A., 1986. Inheritance of tomato fiuit quality components. Plant Breeding Reviews 4: 273-311

Surles, R.L., Ning Weng, P.W. Simon \& S.A. Tanumihardjo, 2004. Carotenoid profiles and consumer sensory evaluation of specialty carrots (Daucus carota, L.) of various colors. J. Agric. Food Chem. 52: 3417-3421.

van den Berg, H., R. Faulks, H.F. Granado, J. Hirschberg, B. Olmedilla, G. Sandmann, S. Southon \& W. Stahl, 2000. The potential for the improvement of carotenoid levels in foods and the likely systemic effects. J. Sci. Food Agric. 80: 880 912
Vieira, J.V., P.T. Della Vecchia \& H. Ikuta, 1983. Cenoura 'Brasilia' . Hort. Bras. 1: 42

Vilmorin, M. Notice sur l'amelioration de la cartotte sauvage, 1859 In. L. Vilmorin (ed.), Notice sur l'amelioration des plantes par le semis, pp. 5-29. Librairie Agricole, Paris.

Waters Corporation, 1994. Millennium Chromatography Manager Software user's guide version 2.1, Waters Corporation, Milford.

WHO, 2001. Wond Heaitu Orgamization: Gloúa' prevalence of vitamin A deficiency. Micronutrient Deficiency Information System, MDIS Working Paper No. 2.

Ye, X., A.B. Salim, A. Kloti, Z. Jing, P. Lucca, P. Beyer \& I. Potrykus, 2000. Engineering the provitamin $A$ (beta-carotene) biosynthetic pathway into (carotenoid-free) rice endosperm. Science 287:303305. 